\title{
Nonsyndromic Phocomelia: A Case Series
}

\section{Anurag Sharma1, Rajesh Chaudhary², Ankit Shukla3, Usha K Chaudhary4, Kullbhushan Sharma ${ }^{5}$ and Atul Gupta ${ }^{6}$}

\author{
${ }^{1}$ Department of Obstetrics and Gynaecology, Zonal Hospital Dharamshala HP, India \\ ${ }^{2}$ Department of Surgery, Dr. R.P. Govt. Medical College Kangra, Tanda HP, India \\ ${ }^{3}$ Department of Anaesthesia, Dr. R.P. Govt. Medical College Kangra, Tanda HP, India \\ ${ }^{4}$ Department of Surgery, Zonal Hospital Dharamshala HP, India \\ ${ }^{5}$ Department of Peadiatrics, Zonal Hospital Dharamshala HP, India
}

Corresponding author: Dr. Rajesh Chaudhary, MS, Senior Resident, Department of Surgery, Dr. RP Govt. Medical College Kangra at Tanda HP, India, E-mail: topgun.chaudhary@gmail.com

Received: Jan 25, 2016; Accepted: Feb 18, 2016; Published: Feb 23, 2016

Citation: Sharma A, Chaudhary R, Shukla A, et al. Nonsyndromic Phocomelia: A Case Series. Transl Biomed. 2016, 7:1.

\section{Abstract}

Phocomelia is a rare congenital disorder seen in new borns. It means 'seal limbs' derived from greek language. The incidence of this disorder is very low, and true phocomelia cases are further low, hence there are not many studies on this disorder. Thalidomide was responsible for bringing this drug into limelight. In this report we have described two cases of isolated nonsyndromic phocomelia where there was no history to drug or radiation exposure during intra-uterine period thus showing that there are factors other than thalidomide, which needs to be studied.

Keywords: Embryopathy; Nonsyndromic phocomelia; Phocomelia; Retinoic acid; Thalidomide

\section{Introduction}

Phocomelia is a rare congenital disorder seen in new borns. It means 'seal limbs' derived from greek language. There are several forms of phocomelia, the majority of which are characterised by a variety of malformations. In some of these syndromic (multisystem) phocomelias gene mutations on different chromosomes have been found and the disorders described as autosomal recessive [1,2]. Nonsyndromic cases of phocomelia are rare. The most common causative agent studied in association with this disorder is thalidomide. It was used as an antiemetic drug but was discontinued for it's teratogenic effect. Recently it has been used for many disorders like leprosy in some developing countries giving rise to an increased incidence of phocomelia. Most commonly this disorder affects the upper limbs and more commonly on left side. The defect is unilateral more than bilateral. The time period between 24 and 33 days after fertilization is critical for the normal limb development. The incidence of phocomelia varies from 0.6 per 1,00,000 live births to 4.2 per 1,00,000 live births throughout the world but the incidence of true phocomelia is not exactly known [3]. We present these two cases of true phocomelia involving the left upper limbs.

\section{Case 1}

A woman with 2 year old boy presented to the outpatient department for plastic surgery consultation. The baby was a full term normal vaginal delivery born to a 25 year old female at a local hospital. The birth weight was $2.65 \mathrm{~kg}$. At birth his left upper limb was malformed. There was no developmental delay. There was no history of consanguinity. There was no history of any drug or x-rays exposure during the pregnancy. There was no history of any exanthematous fever during the pregnancy. There was no history of similar disorder in the family. On examination the child was conscious and well alert. The left upper limb was deformed with no hand and forearm 2 $\mathrm{cm}$ below the elbow joint. Only a soft tissue growth could be seen below the elbow joint. On chest auscultation normal heart sounds were audible. No other deformity was seen. So the child was diagnosed as isolated phocomelia (Figure 1).

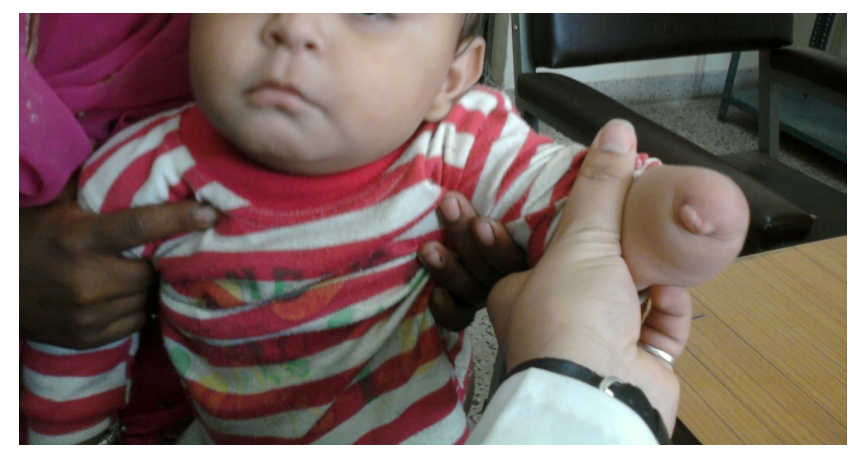

Figure 1 Showing the malformed left upper limb with no hand and forearm just below the elbow joint 


\section{Case 2}

A female child was born to a 25 year old primigravida after lower segment caesarean section at 38 weeks of intrauterine pregnancy, for breech presentation. The baby was weighing $2.7 \mathrm{~kg}$ with left upper limb deformity. The forearm and hand were missing on the left arm $2.5 \mathrm{~cm}$ below the elbow joint (Figure 2). The baby cried immediately after birth and there was no other congenital anomaly noted. There was no history of consanguinity or similar history of birth defects in the family. The mother didnot give any history of drug or radiation exposure during the pregnancy. There was no history of any exanthematous fever during the pregnancy. Thus the child was diagnosed as isolated phocomelia.

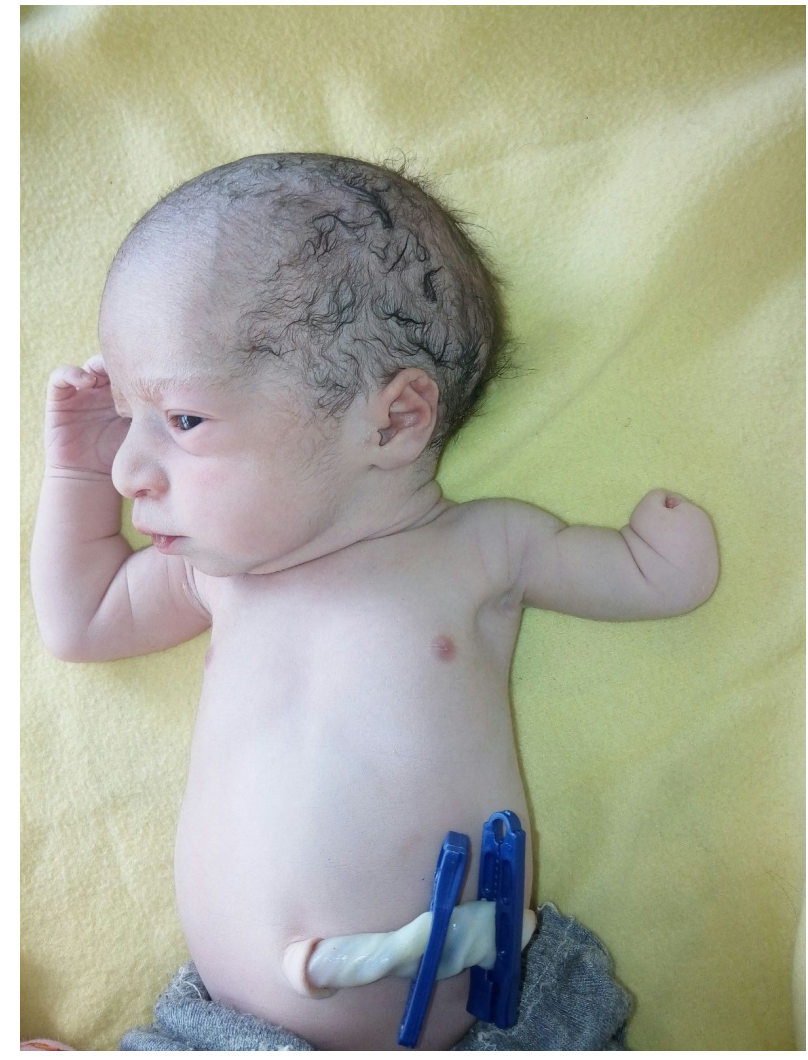

Figure 2 showing absent left hand and forearm just below the elbow joint.

\section{Discussion}

Phocomelia is a rare congenital disorder of limbs. The word has been derived from Greek language which means Seal like limbs. Phocomelia can be seen as a part of the syndrome or an isolated defect of the limbs only. There are at least 25 syndromes associated with phocomelia. True phocomelia has been defined as a total absence of an intermediate segment of the limbs with normal, almost normal, or malformed hands or feet directly attached to the trunk. The first historical evidence of phocomelia dates back to first century BC when an author named Lucretius described similar human beings produced by nature in his poem "De rerum natura". The term phocomelia was coined by Etienne Geoffroy Saint-Hilaire in nineteenth century. The reported incidence of phocomelia varies from 0.6 per 100000 live births to 4.2 per 100000 live births [4]. Usually upper limbs are more commonly affected and it is more common on the left side. Development of upper limb starts by 26th day after fertilization and from 28th day after fertilisation for lower limbs in human beings. Whole process is complete by 56 th day post fertilisation. Lateral plate mesoderm gives rise to appendicular exoskeleton. By the 6th week of intrauterine life hand and foot plates are recognizable and hyaline cartilage can be demonstrated [3]. There are many genes responsible for the growth and differentiation of limbs in a growing foetus. There are many substances which can lead to upregulation or down regulation of these genes. Retinoic acid can lead to proximalisation of a growing limb bud. There are many genes expressed in the growing limb buds which play a role in their growth like those controlling insulin like growth factor, Platelet-derived growth factor and many transcription factors. The important ones are 5 genes of Hox A and D clusters, LIM, tbx, sall and Shox genes [5]. Thalidomide is the most vastly studied drug associated with phocomelia. It is an antiinflammatory drug with immunomodulatory and antiangiogenic effects. Increased cell death can be due to direct activation of the caspase pathways or due to antiangiogenic effect of thalidomide. S-isomer of thalidomide has been thought to be teratogenic but the isomers are interconvertible under physiological conditions. CPS49, an anti-angiogenic analogue of thalidomide is responsible for limb defects. It was commonly used as an anti-emetic drug but a surge in phocomelia cases lead to ban on this drug [6]. Recently the use of this drug for other indications like leprosy in developing countries has led to an increase in cases of phocomelia. Few cases of thalidomide embryopathy from Brazil have been reported where it has been used for treatment of leprosy [7]. USFDA has approved it for many other indications but it is still banned during first trimester of pregnancy [8].

\section{Conclusion}

Phocomelia is a rare congenital disorder producing limb defects in children. True phocomelia cases are further rare. Thalidomide is the most vastly studied among all the causative agents associated with phocomelia but the occurrence of these cases without any exposure to drug or radiation has been seen. Thus other causes which need to be studied. Data available from studies world-over on this disorder is scarse but every case will add to the better understanding of this disorder.

\section{Conflict of Interest}

Authors declare no conflict of interests.

\section{Consent}

Written informed consent was obtained from the patients for publication of this case series and any accompanying 
images. A copy of the written consent is available for review by the Editor-in-Chief of this journal.

\section{Author's Contributions}

Rajesh Chaudhary: Contributed substantially to the conception, design, acquisition of data, analysis and interpretation of data, drafting the article, critical revision of the article and final approval of the version to be published.

Anurag Sharma: Contributed substantially to the Conception and design, Acquisition of data, Critical revision of the article and final approval of the version to be published

Kulbhushan Sharma: Contributed substantially to the Conception and design of the article and final approval of the version to be published.

Ankit shukla: Contributed substantially to the Conception and design, Acquisition of data, Critical revision of the article and final approval of the version to be published.

Atul Gupta: Contributed to the Acquisition of data, Critical revision of the article and final approval of the version to be published.

Usha K Chaudhary: Contributed substantially to the Conception and design, Acquisition of data, Critical revision of the article and final approval of the version to be published.

\section{Acknowledgements}

Nil

\section{References}

Schule B (2005) Inactivating mutations in ESCO2 causes SC phocomelia and Roberts syndrome: no phenotype-genotype correlation. Am J Hum Genet 77: 1117-1128.

Al Qattan MM (2003) A report of two cases of Al-Awadi RaasRothschild syndrome (AARRS) supporting that "apparent" phocomelia differentiates from Schinzel phocomelia syndrome (SPS). Gene 527: 371-375.

Bermejo-Sánchez E (2015) A Worldwide Descriptive Epidemiologic Study in a Large Series of Cases From the International Clearinghouse for Birth Defects Surveillance and Research, and Overview of the Literature. Am J Med Genet C Semin Med Genet 0(4): 305-320.

Aldrovandus U (1988) Monstrorum historia cum paralipomenis historiae omnium animalium. Bologna: N. Tebaldini 1642.

Towers M, Tickle C (2009) Generation of pattern and form in the developing limb. Int J Dev Biol 53: 805-812.

Vargesson N (2009) Thalidomide-induced limb defects: Resolving a 50-year-old puzzle. Bioessays 31: 1327-1336.

Castilla EE, Ashton-Prolla P, Barreda-Mejia E, Brunoni D, Cavalcanti DP, et al. (1996) Thalido-mide, a current teratogen in South America. Teratology 54: 273-277.

U.S. Food and Drug Administration. 2011. http://www.fda.gov/ Drugs/DrugSafety/

PostmarketDrugSafetyInformationforPatientsandProviders/ ucm107296.htm 